- hacia arriba, cercana a la Catedral, que queda a su derecha, vemos una fachada rectangular con una pequeña torre en su lado izquierdo, lo que nos permite identificarla con la Audiencia;

- la masa de la Catedral domina la parte superior, y si su cuerpo es simplemente esbozado por una fábrica a dos aguas con un rosetón en el hastial, destaca la forma pormenorizada en que se ha dibujado la Giralda, elemento igualmente utilizado en pintura para simbolizar la virginal Torre de marfil de las Letanías lauretanas. Aparece perfectamente diferenciada su caña cuadrada almohade, con su almohadillado simulado, los vanos y el lugar donde estuvieron las pinturas de Luis de Vargas, y los cuerpos renacentistas que levantara el manierista Hernán Ruiz II, destacando perfectamente el campanario al que se sobreponen dos cuerpos decrecientes, el último terminado en pequeña bovedita, interrumpiendo este airoso remate la filacteria explicativa del cuadro;

- a la derecha de la Catedral, en una cota más baja, aparece una esbelta torre de dos plantas que no podemos identificar con ningún edificio ubicado por esa zona de la ciudad, ya que el Alcázar no tuvo este tipo de airosos remates, y que nos recuerda las torres comunales italianas, como las de Siena y Florencia, que puede ser considerada un mero recurso del artista a la hora de cerrar ese espacio;

- el resto del entramado callejero lo forman numerosas edificaciones esquematizadas, generalmente de cubiertas a dos aguas, que son difícilmente identificables.

En cuanto al estado de conservación de la pintura podemos calificarlo de bastante lamentable, como se observa en la ilustración, con un deterioro acusado en los últimos años, pues desde 1994 ha perdido parte del recubrimiento pictórico al óleo e incluso del dorado de fondo, ya que se advierte un general enrojecimiento resultado de la afloración del embolado, e incluso éste ha saltado en determinados puntos, permitiendo ver la capa de preparación de la madera.

FERNANDO CRUZ IsIDORO

\title{
LA LLEGADA DEL RENACIMIENTO A SEVILLA: EL PROYECTO DEL CARDENAL HURTADO DE MENDOZA PARA LA CAPILLA DE LA ANTIGUA DE LA CATEDRAL
}

Al recoger Ortiz de Zúñiga en sus Anales de Sevilla la muerte de Diego Hurtado de Mendoza, el 12 de septiembre de 1502, dice de él que fue un prelado «que supo bien imitar al gran Cardenal Don Pedro Gonzalez de Mendoza su tio, que le fué dechado de acciones heroicas, su vida exemplar, su talento grande, su amor á esta iglesia afectuoso» ${ }^{1}$. No yerra el analista al definir al cardenal y arzobispo de Sevilla, en especial al compararlo con su tío y referir su amor a la catedral de Sevilla, que plasmó en la Capilla de Nuestra Señora de la Antigua, lugar que eligió para su enterramiento.

De este modo, Hurtado de Mendoza se embarcó al final de su vida en un proyecto constructivo de gran alcance, que consistía en ampliar y remodelar por completo tal recinto. Para financiar esta empresa hizo una donación a la catedral, detallando el proyecto a levantar, en el que se hacía referencia, de forma pionera en Sevilla, al renacimiento ${ }^{2}$.

\footnotetext{
' Diego Ortiz de Zúñiga, Anales eclesiásticos y seculares de la muy noble y muy leal ciudad de Sevilla. 5 vols. Sevilla, 1988. Vol. 3.․, p. 188. Facsímil de la edición de Antonio María Espinosa y Cárcel, Madrid, 1796.

${ }_{2}$ Archivo de la Catedral de Sevilla, Fondo Histórico General, legajo 89, documento 6/1. Este documento es transcrito al final de este artículo.

Agradecemos a los profesores Morales, Lleó y Marías las sugerencias que nos han dado sobre tan interesante documento.
} 


\section{Análisis del proyecto}

El documento de donación lo encabezan el nombre y los títulos del donante: «Diego Hurtado de Mendoça por la divyna myseraçión cardenal despaña, patriarca de Alexandría, arçobispo de la Santa Yglesia de Sevilla». Tras ello señala que las propiedades que donaba habían sido confiscadas al «liçençiado Antonyo Ynperial, raçionero que fue en esta nuestra Santa Yglesia de Sevilla», y que esos bienes fueron «aplicados a nuestra cámara e fisco e nos pertenesçieron por razón de cierta sentencia» ${ }^{3}$.

A continuación se enumeran tales bienes: «unas casas en esta cibdad de Sevilla en la calle de Castro»; «una tyenda en la calle de Génova» y «en la villa de Marchena un donadío de tierra de pan sembrar que se llama Palençuela» ${ }^{4}$.

El cardenal hacía la donación a «Nuestra Santa Yglesia de Sevilla... con tal cargo y condiçión que la dicha fábrica sea obligada a su costa de acabar la obra de la capilla de Santa Marya del Antigua... que nos mandamos hazer».

Tras ello indica el documento las obras necesarias para terminar la capilla y señala que sería el mayordomo de Fábrica el que administraría los bienes citados, «con acuerdo del deán e cabildo de la dicha nuestra santa yglesia e no en otra manera». Por último, aparecía la firma, el sello placado del prelado y la fecha: «en Sevylla a veynte dos de febrero de myl e quinientos e dos annos», seis meses antes de morir.

Lo más interesante del texto es la relación de obras que disponía para terminar el proyecto, ordenadas en nueve puntos:

- $1 .^{\circ}$ «primeramente que se cierre la obra de la dicha capilla mayor conforme a una muestra que nos tenemos y ha visto el maestro mayor de obras de la dicha nuestra Santa Yglesia e cerrar las dos capillas alta e baxa de la obra que oy día están començadas a obrar».

- 2. $\quad$ «yten se ha de hazer una escalera para subir a la segunda capilla de la sacristanya».

- 3. " «yten se han de hazer dos tribunas, una de un cabo y otra de otro, sobre sus canes, que tengan ocho pies de salida cada una dellas y la longura de la forma que oy día está».

- 4. ${ }^{\circ} \quad$ «ten que acaben la pared que está a la parte de la sacristanía según va començada e de la misma obra que va principiada hasta dar al altar».

- 5. " «yten que la otra pared de qruzero se ha de hazer un arco que salga del dicho qruzero el más alto que pueda ser y se le de el altura que le pertenesca el qual sea rico e de buena obra».

- $6 .^{\circ}$ «yten se ha de hazer una puerta a la sacristanya que sea rica al modo romano».

- 7. «yten que por debaxo del altar de la capilla del cardenal se ha de abrir una puerta e se ha de hacer un canuto debajo del altar por donde salga el preste dentro de la red a dezir misa por dentro de la Sacristanya».

- 8. ${ }^{\circ}$ «yten se ha de hacer la fornezía de dos ventanas una en la capilla mayor y otra en la sacrystanía».

- 9. $\quad$ «ten se han de hacer escudos de armas para poner donde nos mandaremos».

\footnotetext{
${ }^{3}$ Ortiz de Zúñiga, que alude muy tangencialmente a esta donación, dice que la condena se debió a la condición judaizante del acusado, del que omite su nombre. Diego Ortiz de Zúñiga, Anales... op. cit. Pp. 187 y 188 . Curiosamente, otra obra clave del primer renacimiento sevillano, la Casa de Pilatos, también tuvo su origen en la confiscación inquisitorial de unas casas por el carácter judaizante de sus propietarios. Vicente Lleó Cañal, La Casa de Pilatos. Madrid, 1998, p. 15.

${ }^{4}$ De los bienes se indican sus lindes y que estaban arrendados. Ortíz de Zúñiga sólo cita el donadío de Palenzuela, que sitúa en Carmona. Diego Ortiz de Zúñiga, Ibidem
} 
La lectura de estos apartados indica que las obras de la capilla de la Antigua estaban en 1502 muy atrasadas, a pesar de que se habían empezado hacia 1496, según Gestoso ${ }^{5}$. Pensamos que el inicio de la remodelación de este recinto se debería a que Hurtado de Mendoza, tras ser nombrado Cisneros arzobispo de Toledo a la muerte de Pedro González de Mendoza en 1495, comprendió que su cursus honorum iba a terminar en Sevilla y no en la ansiada sede toledana, por lo que decidió preparar su enterramiento en la catedral hispalense ${ }^{6}$.

No obstante, a su muerte, como indica el primero de los puntos, aún no estaba cerrada su bóveda, la cual, al igual que todo el recinto, debía terminarse conforme a un proyecto que el prelado había mostrado al maestro mayor del templo. En él había dos sacristías, una alta y otra baja, no terminadas y que debían ser comunicadas mediante una escalera ${ }^{7}$.

A continuación, el documento alude a dos tribunas de algo más de dos metros de vuelo. También dispone la conclusión del muro oeste y la apertura en el este de una puerta para comunicar la capilla con el crucero del templo. Tal vano debería ser de gran altura y «rico e de buena obra». De esta forma se daba un acceso digno a la capilla, ya que su entrada natural, por los pies del recinto, estaba entonces parcialmente taponada, al encontrarse allí el muro sobre el que fue pintada la Virgen de la Antigua y que no se trasladó a su actual emplazamiento hasta $1578^{8}$.

Continúa el proyecto refiriendo que la puerta de la sacristía sería «al modo romano», lo que evidencia su impronta clásica en una fecha extraordinariamente temprana: 1502. También alude a las obras necesarias para comunicar el altar de la Virgen de la Antigua con la sacristía, lo que facilitaría el tránsito de los sacerdotes encargados de su culto. Por último, refiere la necesidad de abrir dos ventanas, una en la capilla y otra en la sacristía, y de hacer escudos del cardenal para ubicarlos donde éste mandase, lo que muestra su intensa participación en la empresa.

Con los datos de que disponemos no es fácil reconstruir el proyecto de Hurtado de Mendoza, saber en qué medida se realizó ni cuánto queda del mismo. Ello se debe, en primer lugar, a que el documento tratado sólo refiere las labores necesarias en 1502 para terminar la capilla. A ello hay que sumar que las obras se prolongaron considerablemente tras la muerte del prelado, como enseguida veremos, lo que propició la modificación del proyecto original. Además, este recinto sufrió dos grandes reformas con posterioridad, la primera al ser trasladada la Virgen a su actual emplazamiento en 1578, realizada por el maestro mayor Asensio de Maeda, y la segunda en 1734, auspiciada por el arzobispo Luis de Salcedo y Azcona, que también eligió este lugar para su enterramiento ${ }^{9}$. Pese a ello, hay que indicar que la planta y el alzado que actualmente tiene la capilla son los que le dio Hurtado de Mendoza. El prelado

\footnotetext{
5 José Gestoso y Pérez, Sevilla monumental y artística. 3 vols. Sevilla, 1984. Vol. 2. ${ }^{\circ}$, pp. 498-499. Facsímil de la edición príncipe, Sevilla, 1889-1892.

6 Sobre la vida de Hurtado de Mendoza remitimos a: José Alonso Morgado, Prelados sevillanos o episcopologio de la Santa Iglesia Metropolitana y Patriarcal de Sevilla. Sevilla, 1899-1904, pp. 386-393; Francisco Layna Serrano, Historia de Guadalajara y sus Mendozas en los siglos XV y XVI. 4 vols. Madrid, 1942. Vol. 2º, pp. 237-240 y Carlos Ros, Los arzobispos de Sevilla. Luces y sombras de la sede hispalense. Sevilla, 1986, pp. 118-121.

7 A estas sacristías se refiere como a «dos capillas». El diccionario de García Salinero define capilla como «pieza de una catedral o iglesia». Fernando García Salinero, Léxico de alarifes de los Siglos de Oro. Madrid, 1968, ad vocem.

${ }^{8} \mathrm{El}$ muro sobre el que está pintada la Virgen de la Antigua es un resto de la mezquita almohade, respetado cuando ésta se derribó para levantar la catedral gótica. En el nuevo edificio se encontraba exento, taponando en parte la comunicación de la capilla con las naves del templo. Debido a tan extraña localización, en 1578 se decidió trasladarlo a su actual emplazamiento. Álvaro Recio Mir, «Asensio de Maeda y la transformación de la Capilla de la Antigua de la Catedral de Sevilla (1578-1601)», Cuadernos de arte de la Universidad de Granada, 29, pp. 51-67. Granada (1998), pp. 52-55.

9 Sobre ambas reformas véanse respectivamente: Álvaro Recio Mir, «Asensio de Maeda...», op. cit. y José Gestoso y Pérez, Sevilla... op. cit., pp. 510-513.
} 
dobló la superficie y la altura del primitivo recinto, lo cual, a pesar de las reformas, se ha mantenido ${ }^{10}$. La visión exterior del conjunto es muy gráfica al respecto, ya que muestra dos grandes volúmenes que sobresalen de la estructura catedralicia, el de la capilla y el de su sacristía (Fig. 1)

No obstante, el documento de 1502 indica que entonces la capilla no estaba cerrada. Ello lo confirma el relleno de loza de su bóveda, que la data en $1512^{11}$. Tal fecha apunta a que la debió realizar Alonso Rodríguez, maestro mayor del templo entonces y que fue expulsado de su cargo el 7 de diciembre de ese año, debido a que en 1511 se había hundido el cimborrio que él mismo había cerrado en $1506^{12}$.

Sin embargo, el documento que analizamos no refiere cómo era la bóveda del proyecto auspiciado por el cardenal, lo que impide saber si coincidía con la compleja cubierta estrellada que a la postre se realizó, que parece lo más lógico.

A la capilla se la dotó de una sacristía de dos plantas, o sacristías alta y baja comunicadas por una escalera, como disponía la donación del prelado. Esta escalera no se mandó construir hasta $15266^{13}$ y aún no se había terminado en 1534 , momento en el que trabajaría en ella Diego de Riaño ${ }^{14}$.

En la actualidad la sacristía baja se conserva intacta y en uso. No obstante, su portada se hizo hacia $1578^{15}$, por lo que no sabemos si se construyó el acceso a la romana referido en el documento. Su interior es un espacio cuadrado con una cabecera a la que se accede por un arco gótico de medio punto. Su cubierta es de nuevo estrellada, pero mucho más sencilla que la de la capilla. No obstante, el semejante tratamiento de los nervios nos hace pensar que ambas bóvedas son obras del mismo autor ${ }^{16}$, que todo parece indicar que sería Alonso Rodríguez, al menos autor material, ya que ninguna de las dos cubiertas estaba terminada en 1502.

La sacristía alta fue cubierta por una sencilla bóveda de crucería y ha perdido su primitiva comunicación con la inferior, siendo sólo practicable desde las bóvedas del templo ${ }^{17}$. De la

\footnotetext{
${ }^{10}$ Lógicamente, al ser la Virgen trasladada en 1578 de los pies a la cabecera de la capilla se invirtió su disposición litúrgica.

1 Fernando Amores Carredano y Nieves Chrisvert Jiménez, «Tipología de la cerámica común bajomedieval y moderna sevillana (ss. XV-XVII): I, la loza quebrada de relleno de bóvedas». Spal, nº 2, pp. 269-325. Sevilla (1993), p. 272. En el relleno de esta bóveda se han encontrado nueve tipologías cerámicas, fechadas en 1512 .

En 1703 esta cubierta se encontraba en muy mal estado, por lo que Leonardo de Figueroa, Lorenzo Fernández de Iglesias, Antonio Gil Gastado y Jerónimo Franco emitieron diversos informes que pusieron en evidencia que, a raíz de un terremoto, algunos de sus sillares «se habían desmoronado por ser salitrosa», recomendando que se reparase. Este arreglo fue auspiciado por Salcedo y Azcona y realizado por Diego Antonio Díaz en 1734, que luego doró y estofó la obra. Hasta ahora se pensaba que lo realizado entonces había sido una bóveda prácticamente nueva siguendo el modelo de la primitiva, pero su relleno indica que la actual es la primitiva, que fue realizada en 1512 y sólo reparada en el siglo xviII. Véase al respecto: Heliodoro Sancho Corbacho, Arquitectura sevillana del siglo xvirI. Vol. VII de Documentos para la historia del arte en Andalucía. Sevilla, 1934, p. 215 y Teodoro Falcón Márquez, La Catedral de Sevilla (Estudio arquitectónico). Sevilla, 1980, p. 64.

12 José Gestoso y Pérez, Sevilla monumental..., op. cit., nota 6, p. 42.

${ }^{13}$ En la reunión capitular del 8 de junio de 1526 se acordó: «fazer e hedificar la escalera en la Capilla de la Antigua para la cámara alta sobre la sacristía, con todas las puertas e lo necesario de fazerse en ella para que alli puedan poner los almarios e arcas de las sepulturas de los achivos de esta santa iglesia». Teodoro Falcón Márquez, La Catedral de Sevilla..., op. cit., p. 63, nota 165. Peraza indica que la sacristía alta servía en los años treinta del siglo Xvi de «aposento alto para los que aquí vienen a velar». Luis de Peraza, Historia de Sevilla. Edición de Francisco Morales Padrón. Sevilla, 1996, p. 47.

14 Alfredo J. Morales, «La arquitectura de la catedral de Sevilla en los siglos xvı, xvII y xviII. La Catedral de Sevilla. Sevilla, 1991, p. 186.

15 Alfredo J. Morales, «La arquitectura de la Catedral...» op. cit., p. 205.

16 La estrella que dibuja la bóveda de la sacristía baja se repite, con dos nervios más, en cada uno de los cuatro módulos que configuran la cubierta de la capilla.

17 También ha perdido su función original, usándose hoy en día como almacén. Sabemos que fue reparada en 1536. Teodoro Falcón Márquez, Ibidem. Ello quizás se debió a que entonces se terminase su escalera de acceso.
} 

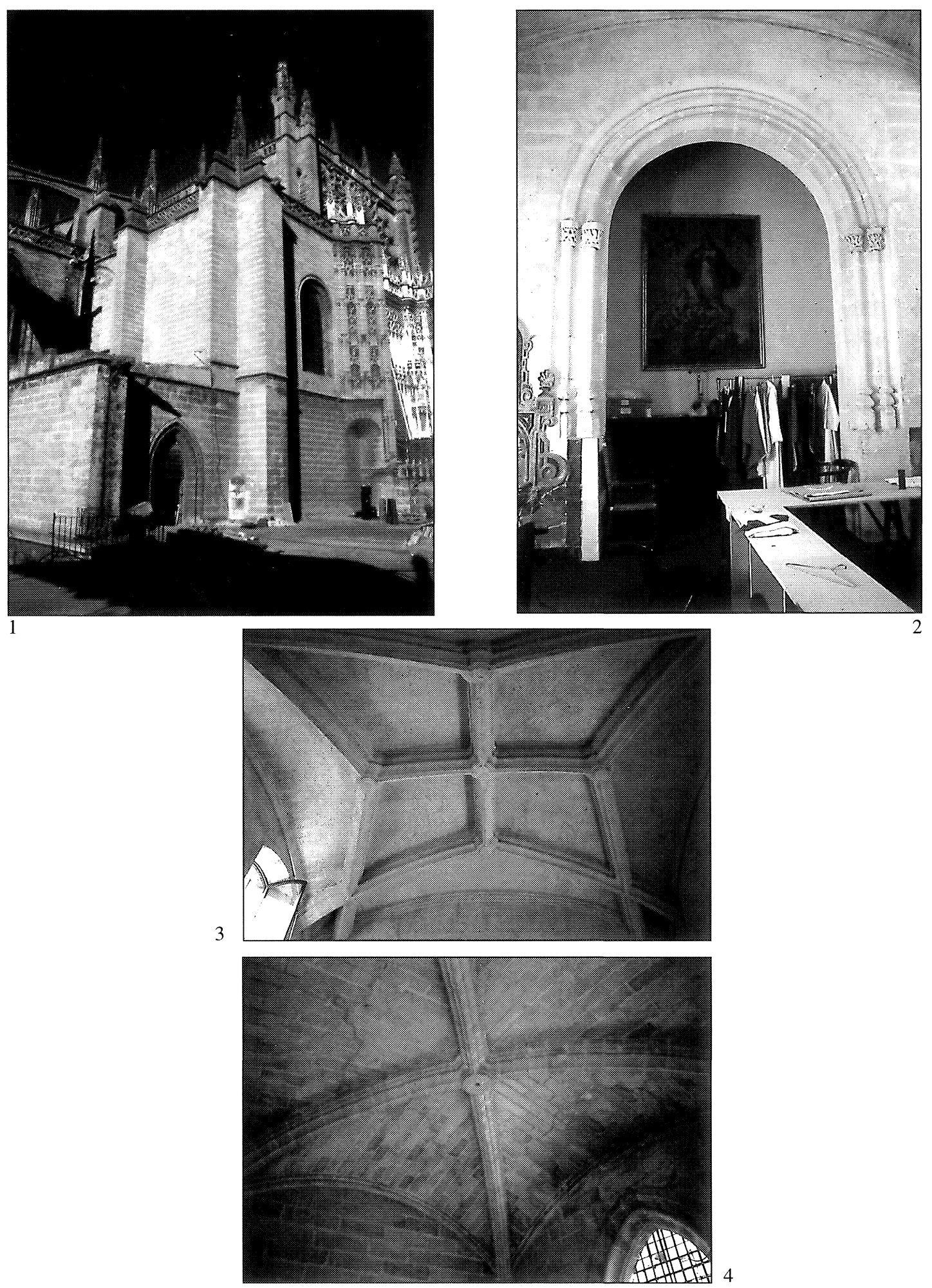

Fig. 1. Catedral de Sevilla, exterior de la capilla de Nuestra Señora de la Antigua. Fig. 2. Catedral de Sevilla, cabecera de la sacristía baja de la capilla de la Antigua. Fig. 3. Catedral de Sevilla, bóveda de la sacristía baja de la capilla de la Antigua. Fig. 4. Catedral de Sevilla, bóveda de la sacristía alta de la capilla de la Antigua. 
escalera que comunicaba ambas sacristías no quedan restos, al menos a simple vista, no apareciendo tampoco en la última planimetría del edificio ${ }^{18}$ (Figs. 2-4).

En relación con el arco que comunica la capilla y el crucero del templo, señalado en el punto quinto del documento de donación, se sabe que en 1510 el Cabildo mandó traer piedras de Utrera para su realización. No obstante, la portada plateresca que se encuentra en ese lugar no se inició hasta $1533^{19}$, estando en 1535 todavía en construcción ${ }^{20}$. Debe ser obra de Diego de Riaño, con posible intervención de Martín de Gainza ${ }^{21}$.

También se hicieron, en fecha incierta, las ventanas citadas en la donación, en la cabecera de la capilla y en su sacristía inferior.

En cuanto a las tribunas del punto tercero, sólo sabemos que el cabildo acordó llevarlas a cabo en $15188^{22}$. Desconocemos si llegaron a realizarse, no conservándose en la actualidad ningún resto de las mismas.

Todo ello evidencia que las obras del recinto se prolongaron largamente tras la muerte del prelado, lo que ocasionó la intervención de varios maestros y la alteración de su proyecto, un híbrido en el que primaría el gótico, pero que ya apuntaba las primeras luces del renacimiento.

Lo más interesante de este documento es mostrar a Hurtado de Mendoza como introductor del renacimiento en Sevilla, papel que se le suele asignar a su hermano Íñigo López de Mendoza, segundo conde de Tendilla y primer marqués de Mondéjar, al cual el cardenal le encargó levantar su sepulcro en la capilla de la Antigua. En esta empresa don Íñigo mostró un gusto plenamente renacentista, siendo muy significativa la carta que le envió al maestro mayor de la catedral, Alonso Rodríguez, indicándole que en dicho sepulcro «no se mezcle con la obra ninguna cosa françesa ny alemana ny morisca syno que todo sea romano» ${ }^{23}$.

Efectivamente, el sepulcro, que hizo Domenico di Alessandro Fancelli entre 1508 y 1509, es completamente renacentista y se inspira en el de Paulo II de San Pedro de Roma, obra de Mino da Fiesole y Giovanni Dalmata ${ }^{24}$. No obstante, como acabamos de ver, años antes, en 1502, Hurtado de Mendoza en su híbrido proyecto para la capilla ya incluía elementos clásicos como el arco de acceso a la sacristía, lo que le convierte en el verdadero pionero del renacimiento sevillano. Esto obliga a incluir al cardenal Hurtado de Mendoza entre los grandes mecenas de la familia Mendoza, cosa que se le ha negado hasta el presente ${ }^{25}$, junto a figuras como su tío don Pedro, su hermano don Íñigo o su abuelo, el primer marqués de Santillana.

\section{Lorenzo Vázquez, posible autor del proyecto}

La reforma de la capilla de la Antigua respondía a un proyecto plasmado gráficamente en una traza que el documento de donación denomina «muestra». Nada se dice de su autor, pero

\footnotetext{
18 Alfonso Jiménez Martín e Isabel Pérez Peñaranda, Cartografía de la montaña hueca. Sevilla, 1997, hoja 3.4. No obstante, en el muro este de la sacristía alta hay una puerta cegada que pudo ser el acceso a la escalera, de la que también puede ser testigo una manga o paramento curvo que ocultaría la primitiva escalera al exterior, que por este detalle sería de caracol.

19 Teodoro Falcón Márquez, La Catedral de Sevilla..., op. cit., p. 63.

20 Luis de Peraza, Historia..., op. cit., p. 47.

21 Alfredo J. Morales, «La arquitectaura...», op. cit., pp. 186 y 187.

22 Teodoro Falcón Márquez, La Catedral de Sevilla..., op. cit., p. 63.

${ }^{23}$ Fernando Marías, El largo siglo xvi. Los usos artísticos del Renacimiento español. Madrid, 1989, p. 239.

${ }^{24}$ Sobre este sepulcro véase: Vicente Lleó Cañal, Nueva Roma. Mitología y Humanismo en el Renacimiento sevillano. Sevilla, 1979, pp. 99-103. Antes de realizarse el sepulcro los restos del prelado estuvieron depositados ante la Virgen de la Antigua entre 1502 y 1504 . En agosto de 1504 se mandó al mayordomo de Fábrica que «se faga en la pared adonde ha de star su vulto un arco y se ponga allí la tumba fasta que se haga el vulto». Teodoro Falcón Márquez, La Catedral de Sevilla..., op. cit., p. 63, nota 162.

${ }_{25}$ Véase al respecto: Francisco Layna Serrano, Historia de Guadalajara..., op. cit., p. 240.
} 
resulta evidente que no pudo ser el maestro mayor del templo, entonces Alonso Rodríguez, ya que en dicho documento se especifica que el cardenal había enseñado su «muestra» a ese maestro, lo que supone que él no la había realizado, aunque sería el encargado de llevarla a la práctica como arquitecto catedralicio.

Pero, si no fue Rodríguez, ¿quién hizo tal traza? Teniendo en cuenta que en 1496 Hurtado de Mendoza dispuso que Simón de Colonia visitase las obras de la catedral, cabe la posibilidad de que también le encargase la ampliación de su capilla ${ }^{26}$. Sin embargo, no creemos que eso ocurriese ya que Rodríguez estuvo al servicio del templo a la vez que Colonia, con el que seguro que colaboró, por lo cual, de existir un proyecto de éste, Rodríguez sería el primero en conocerlo y ya sabemos que en 1502 no era así. Además la misión de Colonia se centró en el cimborrio y en la capilla mayor ${ }^{27}$.

Esto nos lleva a formular nuestra hipótesis, en la que partimos de lo único conocido: el maestro mayor de la catedral era ajeno a la «muestra» del cardenal. Por ello hay que buscar a su autor en el entorno del prelado y de la familia Mendoza, lo que conduce a Lorenzo Vázquez.

El descubridor y gran mecenas de este arquitecto fue el cardenal Pedro González de Mendoza, antecesor de su sobrino Diego en la mitra hispalense. Don Pedro edificó el Colegio de la Santa Cruz en Valladolid, donde Vázquez jugó un papel esencial en la introducción del renacimiento en Castilla. A la muerte del Gran Mendoza en 1495, Vázquez siguió al servicio de distintos miembros de esta extensa y linajuda familia castellana. De esta forma trabajó para el primogénito del cardenal, Rodrigo Díaz de Vivar y Mendoza, primer marqués del Zenete, en su castillo de La Calahorra. También sirvió a varios sobrinos de don Pedro, como Luis de la Cerda y Mendoza, primer duque de Medinaceli, en el palacio de Cogulludo, o el ya citado Iñigo López de Mendoza, en el convento de San Antonio de Mondéjar. Este último, principal patrono de Vázquez tras la muerte de su tío, había estado en Italia como embajador de los Reyes Católicos ante Inocencio VIII y era el hermano mayor de Diego Hurtado de Mendoza, que también vivió en Italia cuando el padre de ambos, el primer conde de Tendilla, fue embajador ante Calixto III ${ }^{28}$.

Los dos hermanos tenían, por tanto, una formación y unas inquietudes culturales parejas, entre las que destacaba su interés por el renacimiento, que difundieron por Castilla. No es extraño por tanto que el prelado encargase a su hermano la construcción de su sepulcro, asunto

${ }^{26}$ Colonia, maestro mayor de la catedral entre 1496 y 1498, vino a Sevilla debido a las discrepancias del anterior maestro mayor, Juan de Hoces, con sus aparejadores, Francisco Rodríguez de Sevilla y Pedro Sánchez de Toledo. Teodoro Falcón Márquez, La Catedral... op. cit., p. 126.

${ }^{27}$ Recientemente Javier Gómez Martínez ha atribuido la bóveda de esta capilla a Simón de Colonia. Sin embargo, no recoge el dato de su cronología, 1512, que proporciona su cerámica de relleno, como ya indicamos con anterioridad. El referido autor señala asimismo el carácter alemán de esta bóveda cuádruple, que él compara con la bóveda del crucero del Hospital Real de Santiago, de Antón y Enrique Egas. Javier Gómez Martínez, El gótico español de la Edad Moderna. Bóvedas de crucería. Valladolid, 1998, p. 86. No obstante, en el entorno sevillano hay al menos otro ejemplo de bóveda cuádruple relacionada con ésta, la que cubre la cabecera de la iglesia de Santa María de la Granada, en Niebla (Huelva) Véase al respecto Diego Angulo Íñiguez, Arquitectura mudéjar sevillana. Sevilla, 1932, pp. 120 y 121 y Ana Marín Fidalgo, Arquitectura gótica del sur de Huelva. Huelva, 1982, p. 63 y 155.

${ }_{28}$ Sobre la labor de Vázquez para los Mendoza véase: Manuel Gómez-Moreno Martínez, «Sobre el Renacimiento en Castilla. Notas para un discurso preliminar I. Hacia Lorenzo Vázquez». Archivo Español de Arte y Arqueología, 1, pp. 140. Madrid (1925); Manuel Gómez-Moreno Martínez, «Sobre el Renacimiento en Castilla II. La Capilla Real de Granada». Archivo Español de Arte y Arqueología, 2, pp. 245-288. Madrid (1926); Rosario Díez del Corral Garnica, «Lorenzo Vázquez y la casa del cardenal Pedro González de Mendoza». Goya, 155, pp. 280-285. Madrid (1980); Rosario Díez del Corral Garnica, Arquitectura y mecenazgo. La imagen de Toledo en el Renacimiento. Madrid, 1987, pp. 19 y ss. y Fernando Marías, El largo siglo XVI... op. cit. pp. 254 y ss.

Martínez Tercero apunta la posibilidad de que el Gran Mendoza enviase a Vázquez a Italia en la embajada del segundo conde de Tendilla, para realizar su proyecto en la basílica romana de Santa Cruz. Enrique Martínez Tercero, La primera arquitectura renacentista fuera de Italia. Lorenzo Vázquez en Guadalajara. Guadalajara, 1995, p. 38. 
ya conocido y que muestra la afinidad de gustos de ambos. Por ello parece muy posible que Hurtado de Mendoza acudiera también a su hermano o, mejor, al arquitecto de éste, Lorenzo Vázquez, cuando ideó transformar la capilla de la Antigua. La envergadura de la refoma, la intervención directa del prelado y sus novedades renacentistas apuntan a Vázquez como posible autor de la traza que analizamos. No es inverosímil, por tanto, que el arquitecto visitase Sevilla para realizar este proyecto ${ }^{29}$

También pudo Hurtado de Mendoza contactar con Vázquez con motivo del encargo que le hizo don Pedro de que se ocupase de la realización de su sepulcro en la catedral de Toledo. Así, en su testamento, otorgado el 23 de junio de 1495, especificaba que «todo lo a ello atinente e concerniente se labre e faga según que pareciere al muy reverendo in Cristo padre don Diego Furtado de Mendeza arzobispo de Sevilla nuestro sobrino, el cual rogamos que tome dello cargo en lo faga e mande fazer según que bien visto fuere» ${ }^{30}$. Ello obligaría a don Diego, justo antes de iniciar la reforma de la capilla de la Antigua, a involucrarse en los círculos artísticos de su tío, en los que sobresalía Lorenzo Vázquez ${ }^{31}$.

Después de haber visto todos estos datos creemos posible que este último realizase el proyecto para la remodelación de la capilla de la Antigua de la catedral de Sevilla. La documentación del templo no hace referencia a que Vázquez visitase el edificio, lo que no invalida nuestra hipótesis, ya que, aunque se hubiese dado tal visita, lo lógico es que no quedase registrada en el archivo catedralicio, al ser un encargo privado del prelado, sin la intervención capitular.

En cualquier caso, las obras serían llevadas a cabo en su mayoría por Alonso Rodríguez, como maestro mayor del templo a fines del siglo xv y comienzos del XVI, lo que explicaría la impronta gótica de la estructura de la capilla, en la que luego trabajaron sus sucesores, como ya hemos visto, que modificaron el proyecto original.

\section{APÉNDICE DOCUMENTAL}

Archivo de la Catedral de Sevilla.

Fondo Histórico General, legajo 89, documento 6/1.

Donación de Cardenal Diego Hurtado de Mendoza a la Catedral de Sevilla. 22 de febrero de 1502.

«Don Diego Hurtado de Mendoça por la divyna myseraçión cardenal despaña, patriarca de Alexandría, arçobispo de la Santa Yglesia de Sevilla, por quanto los bienes e hazienda que fueron e fincaron e thenía e poseya el liçençiado Antonyo Ynperial, raçionero que fue en esta nuestra Santa Yglesia de Sevilla, fueron confiscados e apalabrados a nuestra cámara e fisco e nos pertenesçieron por razón de cierta sentencia que contra el dicho liçenciado fue dada e pronunciada, entre los cuales dichos bienes el dicho liçençiado tenya e poseya unas casas en esta dicha cibdad de Sevilla, en la calle de Castro, que tiene en lynde de la una parte con casas del jurado Esquivel e de la otra parte con horrno del dicho jurado e por delante la dicha calle con una tyenda en la calle de Génova pared inmedio de Menavente Barrero, la cual sale de las dichas casas, las quales dichas tenya arrendadas Sebastián de Oria mercader genovés difunto por tiempo de dos años, que començaron primero de enero de myl e quinientos e uno e se cumple en fin de diziembre de myl e quinientos e dos, por presçio de quinze mile maravedís cada un anno, e las agora tiene Gregorio Doria su hermano e así mismo thenía en la villa de Marchena un donadío de tierra de pan senbrar que se llama de Palençuela, que se tyene en linde con el padrón de Carmona e con tierras de Catalina Gonçales, madre de don Enrique, e con tierras de Ruy Ximenes el qual dicho donadio tyene arrendado Ana Muñoz muger de Antón Ximénez Sancho Tebas y Francisco Ximénez y Antón Ximénez de Sancho Teba, sus fijos, en prescio de treze cafizes de pan terçiado, por tiempo de ocho annos por primeros syguyentes que comyençan primero de enero de myl e qui-

\footnotetext{
${ }^{29}$ En este sentido se conocen pagos a Vázquez «por carta fecha en Sevilla» en 1490 que apoyarían esta hipótesis. F. de B. San Román, «Las obras y los arquitectos del Cardenal Mendoza». Archivo español de arte y arqueología, 7, pp. 155161. Madrid (1931), p. 160.

${ }^{30}$ Rosario Díez del Corral Garnica, Arquitectura y mecenazgo..., op. cit., p. 38.

${ }^{31}$ F. de B. San Román, «Las obras...» op. cit.
} 
nientos e dos annos e que cumplen a fin de diziembre de myll e quinientos e nueve annos, e por nuestra voluntad es de dar e donar las dichas casas e tienda e donadio de tierras de pan senbrar de suso contenidas e declaradas a la fábrica de la dicha Nuestra Yglesia de Sevilla. Nos por la presente hazemos merçed de gracia y donación fecha entre byvos e por non revocable agora e para siempre jamás a la dicha fábrica de la dicha Nuestra Santa Yglesia de Sevilla de las dichas casas e tienda e donadío de tierras de pan senbrar de suso contenidas e declaradas, que así el dicho licenciado thenya e poseya, la cual dicha donación le nos hazemos con tal cargo y condición que la dicha fábrica sea obligada a su costa de acabar la obra de la capilla de Santa Marya del Antigua de esta dicha nuestra Santa Yglesia que nos mandamos hazer e las cosas que ha de mandar e fazer acabar son las syguientes: primeramente que se cierre la obra de la dicha capilla mayor conforme a una muestra que nos tenemos y ha visto el maestro mayor de obras de la dicha nuestra santa yglesia e cerrar las dos capillas alta e baxa de la obra que oy día están començadas a obrar; yten se ha de hazer una escalera para subir a la segunda capilla de la sacristanya; yten se han de hazer dos tribunas una de un cabo y otra de otro sobre sus canes que tengan ocho pies de salida cada una dellas y la longura de la forma que oy día está; yten que acaben la pared que está a la parte (vto) de la sacristanía según que va començada e de la misma obra que va principiada hasta dar al altar; yten que la otra pared de qruzero se ha de hazer un arco que salga del dicho qruzero el mas alto que pueda ser y se le de el altura que le pertenesca el qual sea rico e de buena obra; yten se ha de hazer una puerta a la sacristanya que sea rica al modo romano yten que por debaxo del altar de la capilla del cardenal se ha de abrir una puerta e se ha de hacer un canuto debaxo del altar por donde salga el preste dentro de la red a dezir misa por dentro de la sacrystanía; yten se ha de hacer la fornezía de dos ventanas, una en la capilla mayor y otra en la sacrystía; yten se han de hazer escudos de armas para poner donde nos mandaremos e faziendo e compliendo la dicha fábrica todo lo susodicho en la forma e manera e según aquí se contyene por manera e quede todo muy bien perfectamiente fecho e acabado por la dicha fábrica, e que el mayordomo que agora es e de aquí adelante fuese della pueda hazer e faga de las dichas casas e tyenda e donadío de tierras todo lo que quisiere e por bien tovyere e las arrendar e dar tributo e de por vida e en otra qualquier manera, todo en provecho e utilidad de la dicha fábrica con acuerdo del deán e cabildo de la dicha Nuestra Santa Yglesia e no en otra manera, ca por el thenor de la presente çedemos e traspasamos a la dicha fábrica de la Nuestra Santa Yglesia de Sevilla e en el dicho su mayordomo en su nombre todo el derecho e acción e recurso que nos aviamos e thenyamos e nos pertenesçió e pertenesçe en las dichas casas e tienda e donadio de tierra de pan senbrar de suso contenydas e declaradas e todo el señorío utile e dizerto e abción que a ellas e en ellas tenyamos e nos pertenesçía e pudo pertenesçer, por manera que la dicha fábrica de la dicha Nuestra Santa Yglesia aya e quede en ello todo e en las rentas e alogueres dello se le libre e pacificamente sin contradiçión alguna desde día que estas fueron presentadas en cabildo en adelante para siempre jamás en fe de los que mandamos dar e dimos la presente firmada en nuestro nombre e sellada de nuestro sello, dada en Sevylla a veynte dos de febrero de myl e quinientos e dos annos.

\section{Cardenal Arzobispo de Sevilla (rúbrica)}

Por mandato del cardenal mi señor, Diego de Revenga notario apostólico secretario». 